\title{
Take precautions beforehand: calling for clinical trials of pediatric drugs for treating coronavirus disease 2019
}

\author{
Shao-Qing $\mathrm{Ni}^{1} \cdot \mathrm{Qi}^{\mathrm{i}} \mathrm{Bo} \mathrm{Fu}^{1} \cdot \mathrm{Xin}-\mathrm{Yi}_{\mathrm{S}} \mathrm{Shou}^{2} \cdot \mathrm{Qiang} \mathrm{Shu}^{1}$
}

Received: 1 March 2020 / Accepted: 5 March 2020 / Published online: 25 March 2020

(c) Children's Hospital, Zhejiang University School of Medicine 2020

An epidemic of coronavirus disease 2019 (COVID-19) has spread rapidly throughout China and the world since 2019 . As of March 3rd 2020, China had reported a total of 80,304 cases of COVID-19, including 2,946 deaths. Outside China, there are now 10,566 cases in 72 countries and 166 deaths. Of the deaths reported so far, most of them have been elderly men [1-4]. Adults are more likely to be infected with novel coronavirus (SARS-CoV-2) than children; and symptoms are relatively milder in pediatric patients than in adult patients. The same conditions occurred during the SARS and MERS outbreaks. It is still not clear why children seem to be escaping the worst effects of the coronavirus infection [5-7].

Unlike adults, who can actively protect themselves, children are less likely to protect themselves by avoiding touching things or covering their faces when they cough or sneeze [8]. If children with underlying health conditions (such as leukemia, tumor or other immune deficiencies) are infected with COVID-19, the severity of conditions and difficulty of treatments may be unpredictable [9]. In addition, whether the virus will exist for a long time remains to be verified. If SARS-CoV-2 acts like many other viruses (that is, remains long-lived relative to the lifespan of humans), antiviral treatments will face a great challenge, especially in pediatric patients.

The treatment guidelines are very cautious about recommending antiviral drugs for children. Almost all guidelines highlight that there are no effective antiviral drugs for children at present. The Interim Guidance for Diagnosis and Treatment of COVID-19 infection (the Sixth version) issued

Qiang Shu

shuqiang@zju.edu.cn

1 Children's Hospital, Zhejiang University School of Medicine, National Clinical Research Center for Child Health, National Children's Regional Medical Center, Hangzhou 310052, China

2 First Clinical Medical College, Wenzhou Medical University, Wenzhou 325035, China by the National Health Commission of China is only available for adults in the field of antiviral treatments. The recommended antiviral drugs are interferon- $\alpha$ (IFN- $\alpha$ ), lopinavir/ ritonavir, ribavirin, chloroquine diphosphate and arbidol [2] which have been used in the treatment of COVID-19 in adults. Based on the available evidences, IFN- $\alpha$ nebulization can be used in children, and it has shown good safety profiles under most circumstances. However, children are particularly sensitive to the accumulation of chloroquine phosphate in the body, which could possibly induce severe retinopathy, ototoxicity and cardiotoxicity. On the other hand, it lacks data on the safety of using lopinavir/ritonavir and abidor for children under 2 years of age. In the absence of adequate evidence for efficacy and safety, experts have not reached on an agreement on using ribavirin in the pediatric population. Guidelines for diagnosis and treatment of COVID-19 in children (Second Edition) recommend the use of IFN- $\alpha$, lopinavir/ritonavir and ribavirin in children, without specifying age limitation [10]. The recommended dosage of ribavirin infusion varies in different medical literatures. Some suggest intravenous infusion of ribavirin administered at a dose of $10 \mathrm{mg} / \mathrm{kg}$ every time (maximum $500 \mathrm{mg}$ every time), $2-3$ times daily [10], whereas others recommend $10-15 \mathrm{mg} /$ $\mathrm{kg}$ per day, divided into 2-3 times daily [11].

At present, the efficacy and safety, appropriate dosage, course of treatment and mechanism of action for children's anti-coronavirus drugs need to be studied, and that special attention should be paid to the particular adverse reactions and drug interactions in children [10-13].

Based on the current epidemiological survey, the ages of the confirmed COVID-19 cases in children range from days to 17 years old. These children may have no clinical manifestations, such as fever, fatigue, dry cough, abdominal discomfort, nausea, vomiting, abdominal pain, diarrhea and other gastrointestinal symptoms, etc. A case of a 1.5-month-old infant diagnosed with COVID-19 experienced frequent vomiting [1, 2, 4, 14-18]. The clinical characteristics of COVID-19 in children are different from those in adults, and it is likely that differences also exist between children at different ages. 
It is unknown whether the disease process, treatment response and exposure response relationship of children with COVID-19 are like those of adults. According to the guidelines for clinical trials of pediatric drugs, it is not suitable to perform extrapolation on drug efficacy from adults to children. And children are not little adults. So comprehensive and systematic drug safety and efficacy clinical trials in pediatric population should be planned and conducted as early as possible once the clinical trial data of preliminary safety and potential benefits for adults have been acquired [19].

At present, more than 200 clinical trials for COVID-19 treatment have been carried out in medical institutions all over China. The drugs and the therapies include anti-AIDS drugs, influenza medications, glucocorticoid, traditional Chinese medicines/injections, stem cell transplantation, etc. However, drug clinical trials for COVID-19 children are very limited. As of February 28, 2020, one registered drug clinical trial of traditional Chinese medicine for the prevention of COVID-19 infection in children was found in the China Clinical Trial Registry Center; another clinical trial of darunavir and cobicistat for treatment of COVID-19 in children has been registered in ClinicalTrials.gov. The designs of the two clinical trials are not so scientific with unclear age range defined in the inclusion criteria.

Although the proportion of infected children in the pediatric population to the whole population is relatively low, children are still at high risk of infection and should not be neglected. We should take precautions beforehand to carry out the clinical trials of pediatric drugs for the treatment of COVID-19.

It should be emphasized that the ethical principles of pediatric clinical research must be followed before conducting pediatric clinical trials. Experimental drugs should be selected first from the drugs that have already been on the market and have been used in children. All clinical trials designed for pediatric population should follow the principle of "minimum sample size, and minimum pain" as much as possible [20, 21].

In conclusion, SARS-CoV-2 infected "COVID-19" is a new and pandemic disease. There are differences in clinical manifestations between children and adults. It is very necessary for the government, industries and institutes to prepare well in the early stage and to conduct clinical trials to evaluate the safety and efficacy of pediatric medications on the infected children.

Author contributions All authors contributed to the initial discussion. NSQ wrote the first draft; FQB, SXY and SQ contributed papers and guidance to initial submission. After review and request for more information, SQ updated the document; all authors made final recommendations and edits.All authors approved the final version of the manuscript.
Funding No funding was secured for this study.

\section{Compliance with ethical standards}

Ethical approval Not required for this paper.

Conflict of interest The authors have no conflicts of interest to disclose.

\section{References}

1. Zeng LK, Tao XW, Yuan WH, Wang J, Liu X, Liu ZS. First case of neonate infected with novel coronavirus pneumonia in China. Zhonghua Er Ke Za Zhi. 2020;58:E9 (in Chinese).

2. Wei M, Yuan J, Liu Y, Fu T, Yu X, Zhang ZJ. Novel coronavirus infection in hospitalized infants under 1 year of age in China. JAMA. 2020. https://doi.org/10.1001/jama.2020.

3. Del RC, Malani PN. Novel coronavirus-important information for clinicians. JAMA. 2019. https://doi.org/10.1001/jama.2020.

4. Chen F, Liu ZS, Zhang FR, Xiong RH, Chen Y, Cheng XF, et al. First case of severe childhood novel coronavirus pneumonia in China. Zhonghua Er Ke Za Zhi. 2020;58:E5 (in Chinese).

5. Chan JF, Yuan S, Kok K, To KK, Chu H, Yang J, et al. A familial cluster of pneumonia associated with the 2019 novel coronavirus indicating person-to-person transmission: a study of a family cluster. Lancet. 2020;395:514-23.

6. The National Health Commission of China. The Interim Guidance for Diagnosis and Treatment of COVID-19 infection (the Sixth version)" https://www.nhc.gov.cn/yzygj/s7653p/202002/8334a 8326dd94d329df351d7da8aefc2/files/b218cfeb1bc54639af22 7f922bf6b817.pdf. Accessed 3 Mar 2020.

7. Pappas S. Why are children "missing" from coronavirus outbreak cases? LIVESCIENCE. 2020. https://www.livescience.com/whykids-missing-coronavirus-cases.html. Accessed 3 Mar 2020.

8. Notice on prevention and control of pneumonia caused by the new coronavirus in children and pregnant women. The State Council's Joint Prevention and Control Regulations for Pneumonia Outbreaks Caused by Novel Coronavirus Infection. 2020\#17. Feb 2, 2020. https://www.gov.cn/xinwen/2020-02/02/content_54739 39.htm. Accessed 3 Mar 2020.

9. Wang J, Qi H, Bao L, Li F, Shi Y. A contingency plan for the management of the 2019 novel coronavirus outbreak in neonatal intensive care units. Lancet. 2019. https://doi.org/10.1016/S2352 $-4642(20) 30040-7$.

10. Chen ZM, Fu JF, Shu Q, Chen YH, Hua CZ, Li FB, et al. Diagnosis and treatment recommendations for pediatric respiratory infection caused by the 2019 novel coronavirus. World J Pediatr. 2020. https://doi.org/10.1007/s12519-020-00345-5.

11. Wang Y, Tian DL, Sun YY, Bo YL, Zhu LQ. Pharmaceutical care of antiviral drugs in children with new coronavirus pneumonia. Chin Hosp Pharm J. 2020;06:1-4 (in Chinese).

12. Society of Pediatrics, Chinese Medical Association, Editorial Board, Chinese Journal of Pediatrics. Recommendations for the diagnosis, prevention and control of the 2019 novel coronavirus infection in children (first interim edition). Zhonghua Er Ke Za Zhi. 2020;58:E004. https://doi.org/10.3760/cma.j.i ssn.0578-1310.2020.0004 (in Chinese).

13. Working Group for the Prevention and Control of Neonatal 2019nCoV Infection in the Perinatal Period of the Editorial Committee of Chinese Journal of Contemporary Pediatrics. Perinatal and neonatal management plan for prevention and control of 2019 
novel coronavirus infection (1st edition). Zhongguo Dang Dai Er Ke Za Zhi. 2020;22(2):87-90 (in Chinese).

14. Wang XF, Yuan J, Zheng YJ, Chen J, Bao YM, Wang YR, et al. Retracted: Clinical and epidemiological characteristics of 34 children with 2019 novel coronavirus infection in Shenzhen. Zhonghua er ke za zhi. 2020;58:E8 (In Chinese).

15. Feng K, Yun YX, Wang XF, Yang GD, Zheng YJ, Lin CM, et al. Analysis of CT features of 15 Children with 2019 novel coronavirus infection. Zhonghua Er Ke Za Zhi. 2020;58:E7 (In Chinese).

16. Cai JH, Wang XS, Ge YL, Xia AM, Chang HL, Tian H, et al. First case of 2019 novel coronavirus infection in children in Shanghai. Zhonghua Er Ke Za Zhi. 2020;58:E2 (In Chinese).

17. Zhang YH, Lin DJ, Xiao MF, Wang JC, Wei Y, Lei ZX, et al. 2019-novel coronavirus infection in a three-month-old baby. Zhonghua Er Ke Za Zhi. 2020;58:E6 (In Chinese).
18. Chen ZM, Fu JF, Shu Q. New coronavirus: new challenges for pediatricians. World J Pediatr. 2020. https://doi.org/10.1007/s1251 9-020-00346-4.

19. National Medical Products Administration. Technical guidelines for drug clinical trials in pediatric population. Mach 7, 2016. https ://www.sda.gov.cn/WS01/CL0087/146408.html. Accessed Mar 3 2020.

20. Ni SQ, Shou XY, Yu HM, Qi LY, Li CM, Shu Q. Special considerations for risk in pediatric clinical studies. J Clin Pediatr. 2017;35:636-40 (In Chinese).

21. Ni SQ, Qi LY, Li CM, Yu HM. Informed consent for pediatric clinical studies. J Clin Pediatr. 2017;35:236-40 (In Chinese).

Publisher's Note Springer Nature remains neutral with regard to jurisdictional claims in published maps and institutional affiliations. 